\title{
Antioxidant activity of faba bean extract and fractions thereof
}

\author{
Ryszard Amarowicz $^{\mathrm{a}^{*}}$ and Fereidoon Shahidi ${ }^{\mathrm{b}}$
}

\begin{abstract}
anstitute of Animal Reproduction and Food Research, Polish Academy of Sciences, Tuwima Street 10, 10-748 Olsztyn, Poland
bDepartment of Biochemistry, Memorial University of Newfoundland, St. John's NL, Canada A1B 3X9

*Corresponding author: Ryszard Amarowicz, Institute of Animal Reproduction and Food Research, Polish Academy of Sciences, Tuwima Street 10, 10-748 Olsztyn, Poland. E-mail: r.amarowicz@pan.olsztyn.pl
\end{abstract}

DOI: $10.31665 / \mathrm{JFB} .2018 .2146$

Received: April 18, 2018; Revised received \& accepted: May 18, 2018

Citation: Amarowicz, R., and Shahidi, F. (2018). Antioxidant activity of faba bean extract and fractions thereof. J. Food Bioact. 2: 112118.

\begin{abstract}
Phenolic compounds were extracted into $80 \%(\mathrm{v} / \mathrm{v})$ acetone. The crude extract so obtained was separated into fraction of low-molecular-weight compounds (Fraction I) and a fraction of condensed tannins (Fraction II) using Sephadex LH-20 column chromatography with ethanol and acetone/water $(1: 1, \mathrm{v} / \mathrm{v})$ as respective mobile phases. The antioxidants activities of the crude extract and fractions thereof was investigated in an emulsion system and using ABTS, DPPH, and reducing power assays. Fraction II exhibited a higher antioxidant efficacy than those of the crude extract and Fraction I. In the crude extract, 21 compounds, namely phenolic acids (gallic, $p$-hydroxybenzoic, protocatechuic , $p$-coumaric, ferulic), flavonoids (catechin, epigallo catechin, kaempferol, apigenin, and luteolin derivatives), gallate procyanidins, vanillin, protocatechuic aldehyde, and tryptophan were identified by HPLCDAD-MS. Gallate procyanidin dimer, gallate procyanidins, and acetylated kaempferol hexose were the major phenolics present in the extract.
\end{abstract}

Keywords: Broad bean; Antioxidant activity; Phenolic compounds.

\section{Introduction}

Phenolic compounds of plant origin play important role in food technology as well in human nutrition. As the natural antioxidants they can inhibit or delay the oxidation of nutrients present in food products. In the human organism phenolics can act as protectors of lipids, proteins and DNA against reactive oxygen and nitrogen species (RONS) (Halliwell and Gutteridge, 1992; Willett, 1994). The protective effect of consumption of phenolic-rich grains, legumes, berries, nuts, and oilseeds against several chronic diseases was demonstrated by several researcher groups (Zgang et al., 2018; Chang et al., 2016; Shahidi and Ambigaipalan, 2015; Alshikh et al., 2015; Shahidi and Chandrasekara, 2013).

Legumes are an important source of proteins, starch, oligosaccharides (prebiotics), dietary fibers, vitamins, and minerals in the human diet (Vaz Patto et al., 2015; Flight and Clifton, 2006). The can also serve as a rich source of natural antioxidants and thus can play an important role in caridio- and cancer-protection (Sha- hidi and Ambigaipalan, 2015; Bouchenak and Lamri-Senhadji, 2013; Aparicio-Fernandez et al., 2008; Madhujith and Shahidi, 2005Peeters et al., 2003;; Kolonel et al., 2000; Kushi et al., 1999).

Faba bean (Vicia faba) is a species of Fabaceace family. It is native to North Africa, South America, southwest and south Asia, and is extensively cultivated elsewhere. Like other legumes, faba bean seeds contain phenolic compounds (Turco et al., 2016). The presence of condensed tannins in faba bean was confirmed in the research of Zdunczyk et al. (2018), Jin et al. (2012), Makkar et al. (1997), and Khalil et al. (1995). Antioxidant potential of faba bean was also reported using several assays, including the DPPH (Khan et al., 2015), FRAP (Zdunczyk et al., 2018), as well as DPPH assay and ORAC (Siah et al., 2014). Very high antioxidant capacity of faba bean sprouts was reported by Okumura et al. (2016).

The present study was aimed to determine the polyphenolic profiles and antioxidant properties of faba bean extract and its lowmolecular-weight as well as tannin fractions. 


\section{Materials and methods}

\subsection{Materials}

Faba bean (Vicia faba) seeds of the Polis cultivar were bought from the Plant Breeding Station in Olsztyn (Poland).

\subsection{Chemicals and standards}

Organic solvents, trichloroacetic acid, potassium ferricyanide, and ferric chloride were purchased from the POCh Company (Gliwice, Poland). Linoleic acid, $\beta$-carotene, polyoxyethylenesorbitan monopalmitate (Tween 40), polyoxyethylenesorbitan monopalmitate (Tween 40), butylated hydroxyanisole (BHA), 6-hydroxy-2,5,7,8tetram-ethylchroman-2-carboxylic acid (Trolox), Folin-Ciocalteu's phenol reagent, Sephadex LH-20, 2,2'-diphenyl-1-picrylhydrazyl (DPPH), vanillin, gallic acid, $p$-hydroxybenzoic acid, trans- $p$ coumaric acid, (+)-catechin, (-)-epicatechin, and tryptophan were obtained from Sigma (Poznań, Poland). Luteolin, apigenin, kaempferol, epigallocatechin gallate, catechin gallate, and epicatechin gallate were purchased from Extrasynthese (Genay Cedex, France).

\subsection{Extraction}

Phenolic compounds were extracted from defatted seed samples with hexanes into $80 \%$ acetone $(\mathrm{v} / \mathrm{v})$. Condition of extractions were as follows: $3 \times 30 \mathrm{~min}, 50^{\circ} \mathrm{C}$, a solid-to-solvent ratio of 1:10 (w/v) $(\mathrm{Am}-$ arowicz and Shahidi, 2018). Extraction was carried out at $50{ }^{\circ} \mathrm{C}$ for $30 \mathrm{~min}$ in flasks placed in a shaking water bath (Elpan 357, Wrocław, Poland). Acetone from the combined extract was evaporated using a Büchi rotary evaporator. The sample was then freeze-dried.

\subsection{Column chromatography}

The separation of the low-molecular-weight phenolic and condensed tannin fractions from the crude acetonic extract was carried out using a Sephadex LH-20 column chromatography (Strumeyer and Malin, 1975). A portion of $800 \mathrm{mg}$ of the extract was loaded onto the column $(5 \times 50 \mathrm{~cm})$ packed with gel suspended in $95 \%$ $(\mathrm{v} / \mathrm{v})$ ethanol. Fraction I (low-molecular weight phenolic compounds) was eluted from the gel by using $1 \mathrm{~L}$ of ethanol. For elution of the Fraction II (condensed tannins) $600 \mathrm{~mL}$ of $50 \%(\mathrm{v} / \mathrm{v})$ acetone was used. The organic solvents were then evaporated using a rotary evaporator and any remaining water from Fraction II was removed by lyophylisation.

\subsection{Total phenolic compounds}

The content of total phenolics in the crude extract and Fractions I and II was determined using Folin-Ciocalteou's phenol reagent (Naczk and Shahidi, 1989). The results were expressed as (+)-catechin equivalents per $g$ of the extract or fractions thereof.

\subsection{Condensed tannins}

Condensed tannins were determined using a vamillin $/ \mathrm{HCl}$ colorimetric method (Price et al., 1978). The results obtained were reported as absorbance units at $500 \mathrm{~nm}$ per $1 \mathrm{~g}$ extract or its fractions
$\left(\mathrm{A}_{500} / \mathrm{g}\right)$.

\subsection{UV spectra}

UV spectra of the extract and its fractions dissolved in $80 \%(\mathrm{v} / \mathrm{v})$ methanol was recorded using A Beckman DU 7500 diode array spectrophotometer (Beckman Coulter, Inc., Brea, CA, USA).

\subsection{Determination of total antioxidant activity (TAA)}

The total antioxidant activity was assayed using a Randox kit (Randox Laboratories Ltd., Crumlin, UK) and the analytical procedure outlined by the supplier. Results were expressed as mmol Trolox equivalents (TE)/g extract or fractions thereof.

\subsection{Antioxidant activity in 6-carotene-linoleate model system}

The method of Miller (1970) was carried out for measuring the inhibition of the linoleic acid autoxidation in emulsion system. In this assay, $2 \mathrm{mg}$ of crude extract or Fraction I, or $1 \mathrm{mg}$ of Fraction II dissolved in $0.2 \mathrm{~mL}$ of methanol were added to $5 \mathrm{~mL}$ of a prepared emulsion of linoleic acid and $\beta$-carotene stabilized with Tween 40 . The samples were incubated for $2 \mathrm{~h}$ at $50{ }^{\circ} \mathrm{C}$ and their absorbance was read at 15 min intervals.

\subsection{Reducing power}

Reducing power of the extracts and fraction thereof, was investigated using the method of Oyaizu (1978). The results were expressed by the increase of the sample absorbance read at $700 \mathrm{~nm}$.

\subsection{Antiradical activity against $D P P H^{\bullet}$}

The method described by Yen and Chen (1995) was used for determination of the antiradical activity of the crude extracts and its fractions against DPPH radical. The sample was composed of $2 \mathrm{~mL}$ of methanol, $0.25 \mathrm{~mL}$ of $1 \mathrm{mM}$ solution of DPPH radical, and $0.1 \mathrm{~mL}$ of methanolic solution containing between 0.05 and $2.5 \mathrm{mg}$ of the crude extract or low-molecular-weight fraction - and between 0.1 and 0.5 $\mathrm{mg}$ of fraction tannin fraction. After $20 \mathrm{~min}$ of scavenging reaction at room temperature, the absorbance of the sample was read at $517 \mathrm{~nm}$.

\subsection{HPLC-DAD}

For the HPLC analysis, a Water 2001 system (a quaternary pump, an autoinjector, a diode-array detector, Millenium software; Waters Corp., Milford, MA, USA) was used. Phenolic compounds were separated on a Nova-Pak $\mathrm{C}_{18}$ column $(300 \times 3.9 \mathrm{~mm}, 4 \mu \mathrm{m}$; Waters, Warsaw, Poland), using a gradient of acetonitrile in water according to Dueñas et al. (2004). All analyses of the samples were triplicated. The results were reported as mean value standard deviation.

\subsection{HPLC-ESI-MS}

Mass spectra were recorded using a Hewlett Packard 1100 mass selective detector (MSD, Palo Alto, CA, USA) equipped with an atmospheric pressure chemical ionization (APCI) source and an electrospray 
Table 1. Total phenolics, tannins content, total antioxidant activity in faba bean extract and its fractions and UV spectral data

\begin{tabular}{lllll}
\hline Analyzed material & Total phenolics $(\mathrm{mg} / \mathrm{g})$ & Tannins (Absorbance 500 $\left._{\mathbf{5}} / \mathrm{g}\right)$ & Total antioxidant activity $(\mathrm{mmol}$ trolox eq./g) & $\boldsymbol{\lambda}_{\text {max }}(\mathrm{nm})$ \\
\hline Crude extract & $56 \pm 3$ & $5.96 \pm 0.25$ & $0.88 \pm 0.04$ & 276 \\
Fraction I & $33 \pm 2$ & $3.92 \pm 0.18$ & $0.66 \pm 0.03$ & 276 \\
Fraction II & $285 \pm 14$ & $116 \pm 35$ & $4.21 \pm 0.21$ & 276 \\
\hline
\end{tabular}

ionization (ESI) interface. Mass spectra were recorded in the negativeion mode using a variable fragmentation voltage of 100 and $250 \mathrm{~V}$ for $\mathrm{m} / \mathrm{z} 100-1,000$ and 1,000-2,500, respectively (Dueñas et al., 2004).

\subsection{Identification and quantification of phenolic compounds}

The UV spectra and MS data of the compounds were compared with standards. Some un-known compounds with UV spectra similar, to those of flavonoids and gallates, were identified as their derivatives. Quantitative analysis was made by using an external standard method based on calibration curves for each compound; apigenin, luteolin, and kaempferol were used as standards for flavonoids. The contents of procyanidins were expressed as $(+)$-catechin equivalents.

\section{Results and discussion}

\subsection{Content of total phenolics and condensed tannins}

Fraction II obtained using a Sephadex LH-20 column was charac- terized by the content of total phenolics compounds $(285 \mathrm{mg} / \mathrm{g}$ and $\left.116 \mathrm{~A}_{500} / \mathrm{g}\right)$ condensed tannins $\left(116 \mathrm{~A}_{500} / \mathrm{g}\right)$ was much higher than that was determined in the crude extract and in Fraction I (Table 1). The reason for the relatively low content of total phenolic in fraction I is the presence of sugars in this fraction. The solvent system used in this research was able to also extract sugars/oligosaccharides from faba bean seeds.

The results obtained in this research show that faba bean is a rich source of phenolic compounds as well as condensed tannins. A lower content of total phenolic compounds was previously reported for extracts of pea (Amarowicz and Troszyńska, 2003), white bean (Orak et al., 2016), red bean (Orak et al., 2015), broad bean (Amarowicz and Shahidi, 2017; Boudjou et. al., 2013).

The high content of condensed tannins in the fractions eluted with the mobile phase of acetone-water $(1: 1 ; \mathrm{v} / \mathrm{v})$ from the column packed with Sephadex LH-20 gel was reported before for adzuki bean, broad bean, pea, lentil (Amarowicz et al., 2010, 2009, 2008; Amarowicz and Troszyńska, 2003). The presence of condensed tannins in faba bean seeds determined by vanillin method was reported by Amarowicz et al. (2004) and Baginsky et al. (2013). According to Luo et al. (2015), content of condensed tannins in faba bean extracts ranged from 0.9 to $1.9 \mathrm{~g}$ of gallic acid equiva-

Table 2. Phenolic compounds identified by HPLC-DAD and HPLC-ESI-MS in a faba bean acetonic extract

\begin{tabular}{|c|c|c|c|c|c|}
\hline Peak/compound number & $\lambda_{\max }(n m)$ & {$[\mathbf{M}-\mathbf{H}]^{-}(\mathrm{m} / \mathrm{z})$} & lon fragments $(\mathrm{m} / \mathrm{z})$ & Compounds & Content $(\mu \mathrm{g} / \mathrm{g})$ \\
\hline 1 & 260 & 169 & & Gallic acid & $26.9 \pm 2.3$ \\
\hline 2 & 255 & 153 & & Protocatechuic acid & $18.3 \pm 1.1$ \\
\hline 3 & 280,311 & 137 & & Protocatechuic aldehyde & $6.4 \pm 0.7$ \\
\hline 4 & 255 & 137 & 577,169 & $p$-Hydroxybenzoic acid & $4.7 \pm 0.5$ \\
\hline 5 & 277 & 745 & & Gallate procyanidin dimer & $689 \pm 33$ \\
\hline 6 & 277 & 203 & & Tryptophan & $12.4 \pm 1.8$ \\
\hline 7 & 279 & 289 & & Catechin & $9.4 \pm 0.9$ \\
\hline 8 & 265,348 & 447 & & Kaempferol hexose & $18.8 \pm 1.3$ \\
\hline 9 & 278 & & 289 & Gallate procyanidin & $89.8 \pm 5.4$ \\
\hline 10 & 278 & & 289,169 & Gallate procyanidin & $18.3 \pm 1.1$ \\
\hline 11 & 275 & 457 & & Epigallocatechin gallate & $18.3 \pm 1.1$ \\
\hline 12 & 274 & 442 & 169 & Catechin gallate & $203 \pm 1.3$ \\
\hline 13 & 274 & 442 & 169 & Epicatechin gallate & $363 \pm 16$ \\
\hline 14 & 314 & 163 & & $p$-Coumaric acid & $25.8 \pm 31$ \\
\hline 15 & 276,308 & 151 & & Vanillin & $3.1 \pm 0.8$ \\
\hline 16 & 268,345 & 510 & 447 & Acetylated luteolin hexose & $56.8 \pm 6.3$ \\
\hline 17 & 278 & & 169 & Gallate procyanidin & $30.8 \pm 1.5$ \\
\hline 18 & 268,335 & 593 & 269 & Apigenin hexose & $32.9 \pm 2.6$ \\
\hline 19 & 265,348 & 447 & 285 & Kaempferol hexose & $19.9 \pm 1.0$ \\
\hline 20 & 278 & & 289,169 & Gallate procyanidin & $28.6 \pm 1.5$ \\
\hline 21 & 265,338 & 489 & 447 & Acetylated kaempferol hexose & $76.8 \pm 4.6$ \\
\hline
\end{tabular}




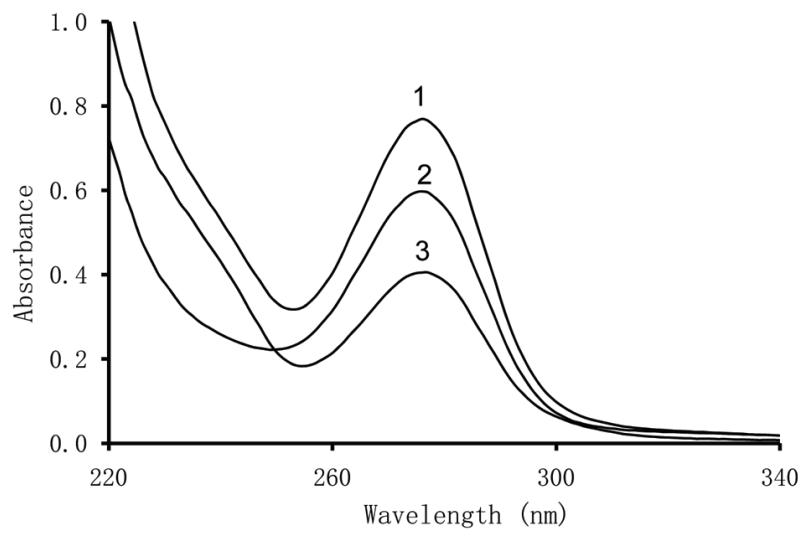

Figure 1. UV spectra of a faba bean acetonic extract and its Fractions. 1 crude extract; 2, Fraction I; and 3, Fraction II).

lents $/ 100 \mathrm{~g}$ extract. In this research the authors precipitated tannins by using polypyrrolidone (PVPP) and used Folin-Ciocalteu phenol reagent for determination of phenolic compounds.

Low values of absorbance obtained for fraction after colour reaction with vanillin (Table 1) were caused by the presence catechins (flavan-3-ols) in this fraction which agrees with the results of HPLC-DAD-MS analysis (Table 2).

\subsection{UV spectra}

The UV spectra recorded for the crude extract of faba bean, and its low-molecular-weight and tannin fractions exhibited maxima at the same wavelength of $276 \mathrm{~nm}$ (Figure 1). The same wavelengths was obtained for the UV spectra of extract of broad bean crude extract and its two fractions (Amarowicz and Shahidi, 2017). The UV spectra depicted in Fig. 1 are agreement with the results from HPLCDAD analysis reported in Table 2 where several separated phenolic compounds showed UV spectra with a maximum close to $276 \mathrm{~nm}$.

\subsection{Antioxidant activity}

The total antioxidant activity (TAA) of the Fractions II (4.21 mmol

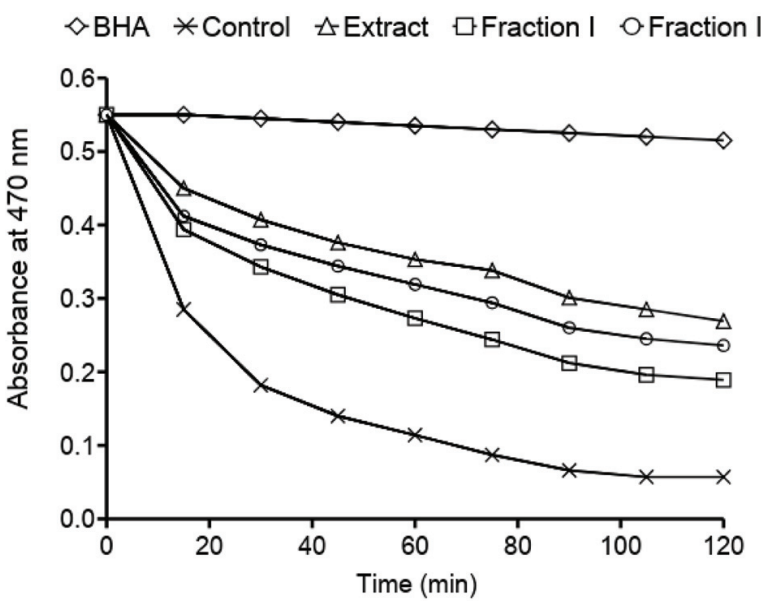

Figure 2. Antioxidant activity of a faba bean acetonic extract and its fractions in a $\beta$-carotene-linoleate model system.

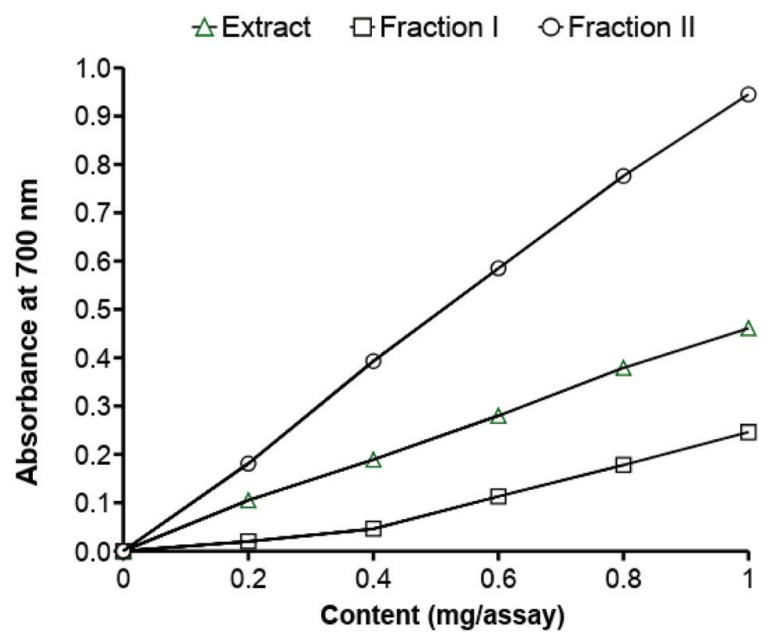

Figure 3. Reducing power of a faba bean acetonic extract and its fractions.
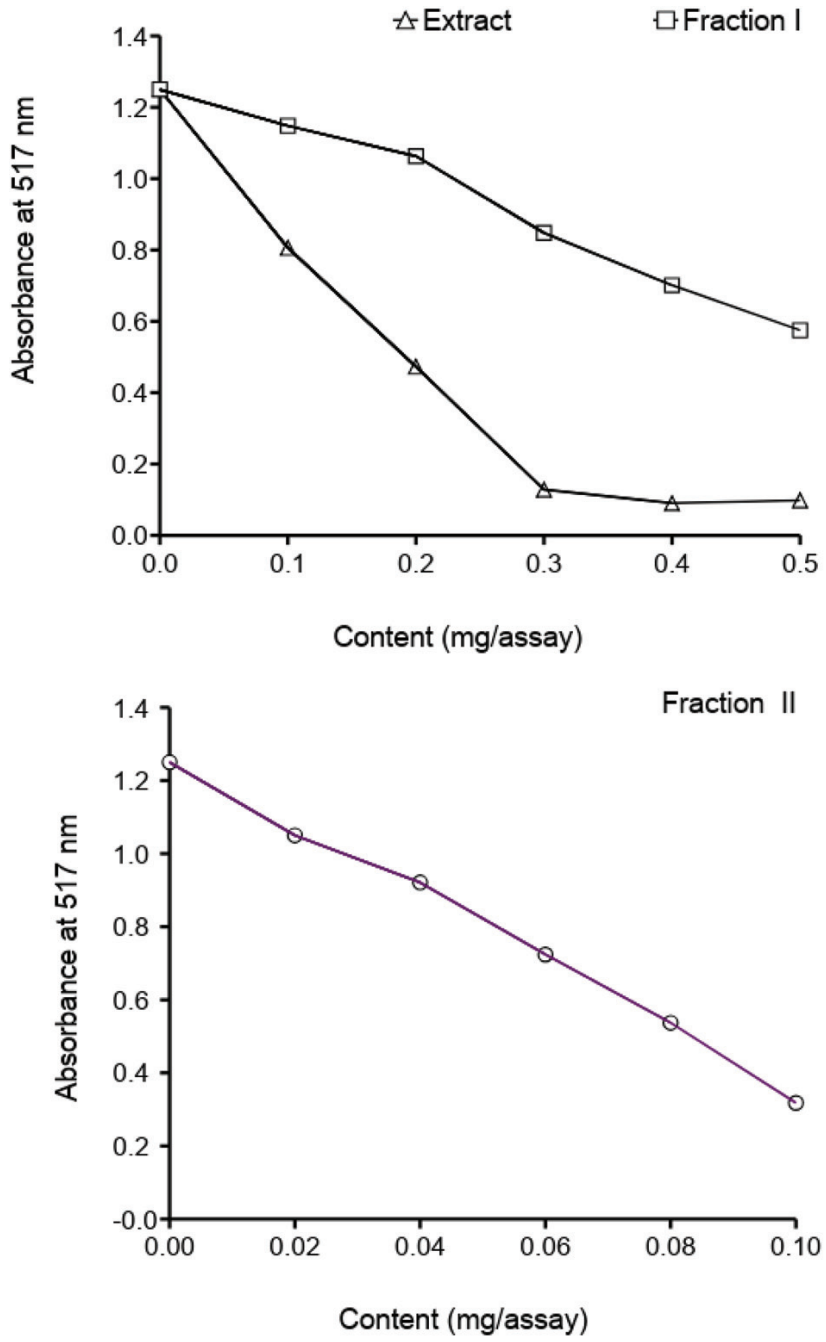

Figure 4. Scavenging effect of a faba bean acetonic extract and its fractions on DPPH radical. 


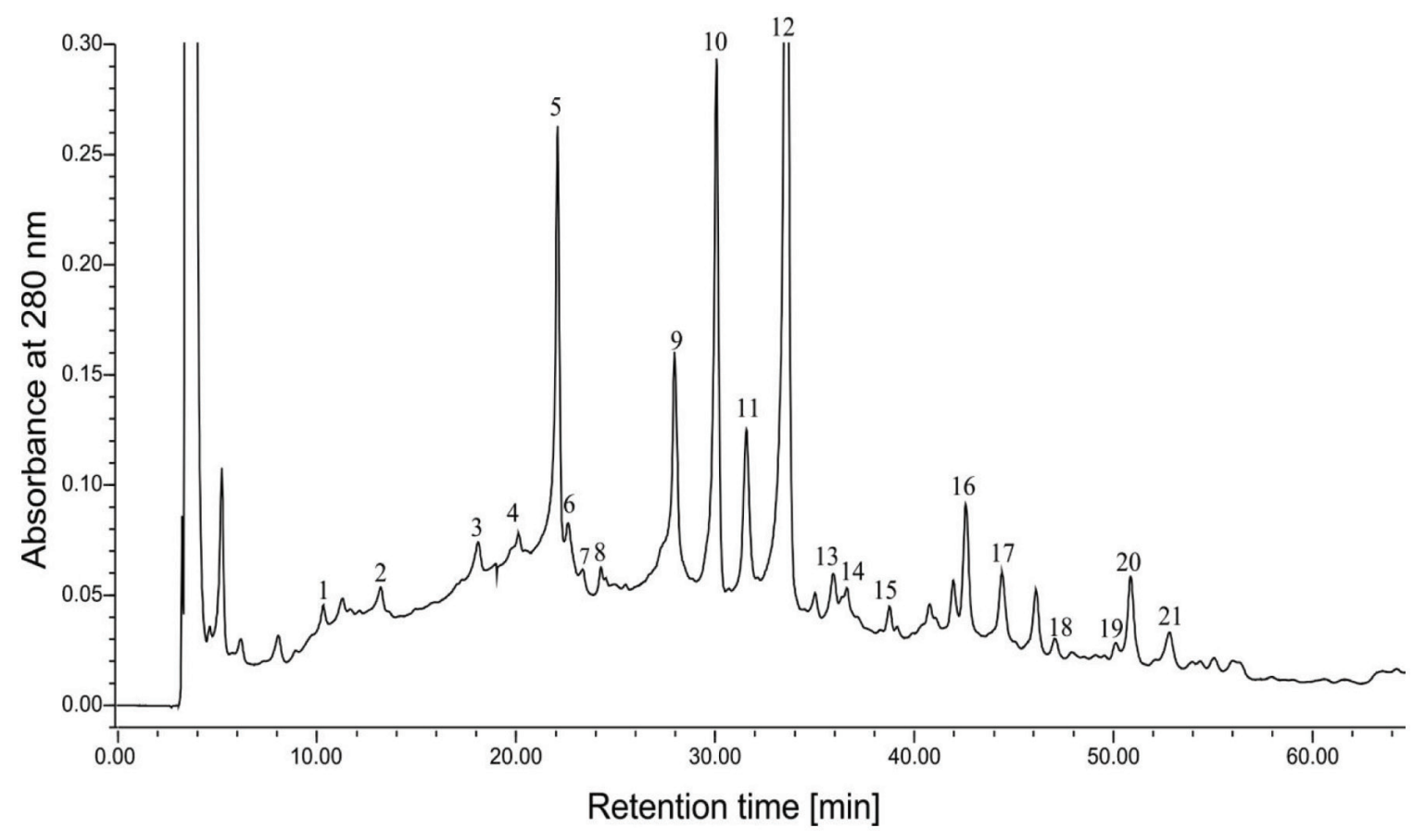

Figure 5. HPLC chromatogram of a faba bean acetonic extract.

TE/g) ) was several times higher than that of crude extract $(0.88$ $\mathrm{mmol} \mathrm{TE} / \mathrm{g}$ ) and Fraction I (0.66 mmol TE/g). The same relation between TAA of the crude extracts and its two fractions were previously reported for adzuki bean (Amarowicz et al., 2008), red lentil (Amarowicz et al., 2009), red lentil (Amarowicz et al., 2010), and broad bean (Amarowicz and Shahidi, 2017). The ability to scavenge ABTS radical cation by phenolic compounds of legume seeds was reported before by several authors (Orak et al., 2015, 2016; Alshikh et al., 2015; Ramírez-Jiménez et al.,2014; Huber et al., 2014). In relation to cited authors, the results of the faba bean obtained in this study are considered to be high.

The crude extract of phenolic compounds of faba beam and its two fractions exhibited antioxidant activity in a $\beta$-carotene-linoleate model system (Figure 2). The effect of extract on the coupled oxidation of linoleic acid and $\beta$-carotene was the highest. However, the amounts of tannins fraction added to the emulsion system was a half of that of the crude extract and Fraction I. The results obtained are important because they prove the fact that condensed tannins also exhibited their antioxidant activity in the emulsion system. Our previous studies in a $\beta$-carotene-linoleate model system found lower antioxidant activity for extracts of leguminous seeds such as broad bean, lentil, adzuki bean, and effectively (Amarowicz and Shahidi, 2017; Amarowicz et al., 2010, 2009, 2008).

Figure 3 depicts the effect of phenolic compounds present in the extract of faba bean and its two fractions (Fraction I and II) on the formation of $\mathrm{Fe}^{2+}$ from $\mathrm{Fe}^{3+} /$ ferricyanide. This effect was monitored by the measuring optical density at $700 \mathrm{~nm}$. The tannin fraction exhibited much stronger reducing activity than those of the crude extract and Fraction I. The strong reducing power obtained for tannins was reported before for peas (Amarowicz and Troszyńska, 2003). However, tannin fractions isolated by Sephadex LH-20 from broad bean. as well as green and red lentils, and adzuki bean, reduced $\mathrm{Fe}^{3+}$ more effectively (Amarowicz and Shahidi, 2017; Amarowicz et al., 2010, 2009, 2008). The ability of phenolic compounds of lentil, common bean, chickpea, yellow pea, green pea, and broad bean for reducing $\mathrm{Fe}^{3+}$ was also assayed by other authors using the FRAP method (Alshikh et al., 2015; Xu and Chang, 2007; Heimler at al., 2005; Ou et al., 2002).

Very strong antiradical activity against $\mathrm{DPPH}^{\bullet}$ was observed for tannin fraction separated from faba bean crude extract (Figure 4). The low-molecular-weight phenolic fraction (Fraction I) was a weak scavengers of the DPPH radical. Antiradical activity of phenolic compounds present in legume seeds extracts was previously confirmed in several studies (Ombra et al., 2016; Veggi et al., 2014; Xu and Chung, 2007; Ranilla et al., 2007). The strong antiradical activity of the condensed tannins separated from plant materials such as canola hulls, beach pea, and evening primrose a were reported by Amarowicz et al. (2000). Radical scavenging activity of condensed tannins as determine by the DPPH assay was described by Muir (1996).

\subsection{Content of individual phenolic compounds}

Figure 5 shows an HPLC chromatogram of a faba bean acetonic extract. The results of HPLC-DAD and HPLC-ESI-MS are given in Table 2. Based on the retention times and UV spectra of commercial standards, the presence of $p$-hydroxybenzoic aldehyde, gallic, protocatechuic, $p$-hydroxybenzoic, trans-p-coumaric acids, (-)-epicatechin, catechin gallate, epicatechin gallate, epigallocatechin gallate, vanillin, and tryptophan in the crude extract of broad bean was confirmed.

Compound 5 showed a negative molecular ion $[\mathrm{M}-\mathrm{H}]^{-}$at $\mathrm{m} / \mathrm{z}$ of 745 and two fragment ions $[\mathrm{F}-\mathrm{H}]^{-}$at $\mathrm{m} / \mathrm{z}$ of 577 and 169 , corresponding to a procyanidin dimer and gallic acid, respectively. This compound was identified as gallate procyanidin dimer. Compounds $9,10,17$ and 20 with a maximum at $278 \mathrm{~nm}$ according to fragment ions $[\mathrm{F}-\mathrm{H}]^{-}$at $\mathrm{m} / \mathrm{z}$ of 289 and 169 corresponding to epicatechin or catechin and gallic acid, respectively, were identified as procyanidin gallates. Compounds 8 and 19 with a negative 
molecular ion $[\mathrm{M}-\mathrm{H}]^{-}$at $\mathrm{m} / z$ of 447 and compounds 18 with a negative molecular ion $[\mathrm{M}-\mathrm{H}]^{-}$at $\mathrm{m} / z$ of 442 were identified as kaempferol and apigenin hexoses, respectively. Based on the UV and MS spectra compounds 16 and 21 were identified as acetylated luteoliv and acetylated kaempferol hexsoses.

Gallate procyanidin dimer, gallate procyanidins, and acetylated kaempferol hexose were the major phenolics present in the extract of faba bean (Table 2). The presence of catechins is very typical for legume seeds (Yeo, J., and Shahidi, 2017. 2015; Alshikhet et al., 2015; Limón et al. 2015; Dueñas et al., 2015). The presence of caffeic, $p$-coumric, ferulic, and sinapic acids was confirmed by Yao et al (2011) in such legumes as lima bean, broad bean, coman bean, pea, jack bean, adzuki bean, rise bean, mung bean. Gallate procyanidin dimer, gallate procyanidins were previously reported in the extracts of broad bean and lentils (Amarowicz and Shahidi, 2017; Amarowicz et al., 2010, 2009). Procyanidin in faba bean were also determined in faba bean by Abu-Reidah et al. (2014) using UHPLC-ESI-QTOF-MS method.

\section{Conclusion}

Faba bean is a potentially valuable legume crops with high antioxidant potential. The tannin fraction separated from the crude extracts using a Sephadex LH-20 column chromatography displayed a stronger antioxidants activity than the low-molecular-weight phenolic fraction. Faba bean seeds may serve as an important can be a valuable component in the diet of the vegetarian and the general populations.

\section{References}

Abu-Reidah, I.M., del Mar Contreras, M., Arráez-Román, D., FernándezGutiéraz, A., and Segura-Carretero, A. (2014). UHPLC-ESI-QTOFMS-based metabolic profiling of Vicia faba L. (Fabaceae) seeds as a key strategy for characterization in foodomics. Electrophoresis 35 : 1571-1581.

Alshikh, N., de Camargo, A.C., and Shahidi, F. (2015). Phenolics of selected lentil cultivars: Antioxidant activities and inhibition of low-density lipoprotein and DNA damage. J. Funct. Foods 18: 1022-1038.

Amarowicz, R., and Shahidi, F. (2017). Antioxidant activity of broad bean seed extract and its phenolic composition. J. Funct. Foods 38: 656662.

Amarowicz, R., and Troszyńska, A. (2003). Antioxidant activity of extract of pea and its fractions of low molecular phenolics and tannins. Pol. J. Food Nutr. Sci. 12: 10-15.

Amarowicz, R., Estrella, I., Hernández, T., Robredo, S., Troszyńska, A., Kosińska, A., and Pegg, R.B. (2010). Free-radical scavenging capacity, antioxidant activity, and phenolic composition of green lentil (Lens culinaris). Food Chem. 12: 705-711.

Amarowicz, R., Estrella, I., Hernández, T., Dueñas, M., Troszyńska, A., Kosińska, A., and Pegg, R.B. (2009). Antioxidant activity of a red lentil extract and its fractions. Int. J. Mol. Sci. 10: 5513-5527.

Amarowicz, R., Estrella, I., Hernández, T., and Troszyńska, A. (2008). Antioxidant activity of extract of adzuki bean and its fractions. J. Food Lipids 15: 119-136.

Amarowicz, R., Troszyńska, A., Baryłko-Pikielna, N., and Shahidi, F. (2004). Polyphenolics extracts from legume seeds: Correlations between total antioxidant activity, total phenolics content, tannins content and astringency. J. Food Lipids 11: 278-286.

Amarowicz, R., Naczk, M., Zadernowski, R., and Shahidi, F. (2000). Antioxidant activity of condensed tannins of beach pea, canola hulls, evening primrose, and faba bean. J. Food Lipids 7: 195-205.

Aparicio-Fernandez, X., Reynoso-Camacho, R., Castano-Tostado, E., Garcia-Gasca, T., Mejia, S.H., and Guzman-Maldonado, S.H. (2008). Antiradical capacity and induction of apoptosis on HeLa cells by a Pha- seolus vulgaris extract. Plant Foods Hum. Nutr. 63: 35-40.

Baginsky, C., Peña-Neira, Á., Cáceres, A., Hernández, T., Estrella, I., Morales, H., and Pertuzé, R. (2013). Phenolic compound composition in immature seeds of fava bean (Vicia faba L.) varieties cultivated in Chile. J. Food Comp. Anal. 31: 1-6.

Boudjou, S., Oomah, B.D., Zaidi, F., and Hosseinian, F. (2013). Phenolics content and antioxidant and anti-inflammatory activities of legume fractions. Food Chem. 138: 1543-1550.

Bouchenak, M., and Lamri-Senhadji, M. (2013). Nutritional quality of legumes, and their role in cardiometabolic risk prevention: A review. J. Med. Foods 16: 185-198.

Chang, S.K., Alasalvar, C., and Shahidi, F. (2016). Review of dried fruits: Phytochemicals, antioxidant efficacies, and health benefits. J. Funct. Foods 21: 113-132.

Dueñas, M., Estrella, I., and Hernández, T. (2004). Occurrence of phenolic compounds in the seed coat and the cotyledon of peas (Pisum sativum L.). Eur. J. Food Res. 219: 116-123.

Dueñas, M., Martínez-Villaluenga, C., Limón, R.I., Peñas, E., and Frias, J. (2015). Effect of germination and elicitation on phenolic composition and bioactivity of kidney beans. Food Res Int. 70: 55-63.

Flight, I., and Clifton, P. (2006). Cereal grains and legumes in the prevention of coronary heart disease and stroke: A Review of the literature. Eur. J. Clin. Nutr. 60: 1145-1159.

Halliwell, B., Gutteridge, J.M.C., and and Cross, C.E. (1992). Free radicals, antioxidants, and human disease: where are we now? J. Lab. Clin Med. 119: 598-620.

Heimler, D., Vignolini, P., Dini, M.G., and Romani, A. (2005). Rapid tests to assess the antioxidant activity of Phaseolus vulgaris $\mathrm{L}$. dry beans. J. Agric. Food Chem. 53: 3053-3056.

Huber, K., Brigide, P., Bretas, E.B., and Canniatti-Brazaca, S.G. (2014). Effect of thermal processing and maceration on the antioxidant activity of white beans. PLoS ONE 9(7): e99325.

Jin, A.L., Ozga, J.A., Lopes-Lutz, D., Schieber, A., and Reinecke, D.M. (2012). Characterization of proanthocyanidins in pea (Pisum sativum L.), lentil (Lens culinaris L.), and faba bean (Vicia faba L.) seeds. Food Res. Int. 46: 528-535.

Khalil, A.H., and Mansour, E.H. (1995). The effect of cooking, autoclaving and germination on the nutritional quality of faba beans. Food Chem. 54: 177-182.

Khan, M.A., Ammar, M.H., Migdadi, H.M., El-Harty, E.H., Osman, M.A., Farooq, M., and Alghamdi, S.S. (2015). Comparative nutritional profiles of various faba bean and chickpea genotypes. Int. J. Agic. Biol. 17: 449-457.

Kolonel, L.N., Hankin, J.H., Whittemore, A.S., Wu, A.H., Gallagher, R.P., Wilkens, L.R., John, E.M., G.R. Howe, G.R., Dreon, D.M., West, D.W., and Paffenberger, R.S. (2000). Vegetables, fruits, legumes and prostate cancer: A multicenter case-control study. Cancer Epid. Biomark. Preven. 9: 795-804.

Kushi, L.H., Meyer, K.A., and Jacobs, D.R. Jr. (1990). Cereals, legumes, and chronic disease risk reduction: evidence from epidemiological studies. Am. J. Clin. Nutr. 70: 451S-458S.

Limón, R.I., Peñas, E., Torino, M.I., Martínez-Villaluenga, C., Dueñas, M., and Frias, J. (2015). Fermentation enhances the content of bioactive compounds in kidney bean extracts. Food Chem. 172: 343-352.

Luo, Y.-W., Wang, Q., Li, J., Wang, Y., Xiao-Xiao, J., and Zheng-Ping, H. (2015). The impact of processing on antioxidant activity of faba bean (Vicia faba L.). Adv. J. Food Sci. Technol. 7: 361-367.

Madhujith, T., and Shahidi, F. (2005). Antioxidant potential of pea beans (Phaseolus vulgaris L.). J. Food Sci. 70: S85-S95.

Makkar, H.P.S., Becker, K., Abel, H.J., and Pawlicki, E. (1997). Nutrient contents, rumen protein degradability and antinutritional factors in some colour- and white-flowering cultivars of Vicia faba beans. J. Sci. Food Agric. 75: 511-520.

Miller, H.E. (1971). A simplified method for the evaluation of antioxidants. J. Am. Oil. Chem. Soc. 48: 91.

Muir, A.D. (1996). Antioxidative activity of condensed tannins. In: Shahidi, F. (Ed.). Natural antioxidants. Chemistry, health effects, and applications. AOCS Press, Champaign, pp. 204-212.

Naczk, M., and Shahidi, F. (1989). The effect of methanol-ammonia-wate treatment on the content of phenolic acids of canola. Food Chem. 31: 159-164 
Okumura, K., Hosoya, T., Kawarazaki, K., Izawa, N., and Kumazawa, S. (2016). Antioxidant activity of phenolic compounds from fava bean sprouts. J. Food Sci. 81: C1394-C-1398.

Ombra, M.N., D’Acierno, A., Nazzaro, F., Riccardi, R., Spigno P Zaccardelli, M., Pane, C., Maione, M., and Fratianni, F. (2016). Phenolic composition and antioxidant and antiproliferative activities of the extracts of twelve common bean (Phaseolus vulgaris L.) endemic ecotypes of southern Italy before and after cooking. Oxid Med Cell Long 2016: 1398298.

Orak, H.H., Karamać, M., and Amarowicz, R. (2015). Antioxidant activity of phenolic compounds of red bean (Phaseolus vulgaris L). Oxid. Comm. 38: 67-78.

Orak, H.H., Karamać, M., Orak, A., and Amarowicz, R. (2016). Antioxidant potential and phenolic compounds of some widely consumed Turkish white bean (Phaseolus vulgaris L.) varieties. Pol. J. Food Nutr. Sci. 66: 253-260.

Ou, B., Huang, D., Hampsch-Woodill, M., Flanagan, J.A., and Deemer, E.K. (2002). Analysis of antioxidant activities of common vegetables employing oxygen radical absorbance capacity (ORAC) and ferric reducing antioxidant power (FRAP) assays: A comparative study. J Agric Food Chem. 50: 3122-3128.

Oyaizu, M. (1878). Studies on products of browning reaction - Antioxidative activities of products of browning reaction prepared from glucosamine. Jap. J. Nutr. 44: 307-315.

Peeters, P.H.M., Boker, L.K., van der Schouw, Y.T., and Grobbee, D.E. (2003). Phytoestrogens and breast cancer risk. Review of the epidemiologic evidence. Breast Cancer Res. Treat. 77: 171-183.

Price, M.L., van Scoyoc, S., and Butler, L.G. (1978). A critical evaluation of the vanillin reaction as an assay for tannin in sorghum grain. J. Agric. Food Chem. 26: 1214-1218.

Ramírez-Jiménez, A.K., Renoso-Camacho, R., Mendoza-Díaz, S., and Loarca-Piña, G. (2014). Functional and technological potential of dehydred Phaseolus vilgaris L. flours. Food Chem. 161: 254-260.

Ranilla, L.G., Genovese, M.I., and Lajolo, F.M. (2007). Polyphenols and antioxidant capacity of seed coat and cotyledon from Brazilian and Peruvian bean cultivars (Phaseolus vulgaris L.). J Agric Food Chem. 55: 90-98.

Shahidi, F., and Ambigaipalan, P. (2015). Phenolics and polyphenolics in foods, beverages and spices: Antioxidant activity and health effectsA review. J. Funct. Foods 18: 820-897.

Shahidi, F., and Chandrasekara, A. (2013). Millet grain phenolics and their role in disease risk reduction and health promotion: A review. J. Funct. Foods 5: 570-581.
Siah, S., Konczak, I., Wood, J.A., Agboola, S., and Blanchard, C.L. (2014). Effect on phenolic composition and in vitro antioxidant capacity of Australian grown faba beans (Vicia faba L.). Plant Foods Hum. Nitr. 69: 85-91.

Strumeyer, D.H., and Malin, M.J. (1975). Condensed tannins in grain sorghum: Isolation, fractionation, and characterization. J. Agric. Food Chem. 23: 909-914.

Turco, I., Ferretti, G., and Bacchetti, T. (2016). Review of the health benefits of faba bean (Vicia faba L.) polyphenols. J. Food Nutr. Research. 55: 283-293.

Vaz Patto, M.C., Amarowicz, R., Aryee, A.N.A., Boye, J.I., Chung, H.-J., Martín-Cabrejas, M.A., and Domoney, C. (2015). Achievements and challenges in improving the nutritional quality of food legumes. Crit. Rev. Plant. Sci. 34: 105-143.

Veggi, P.C., Cavalcanti, R.N., and Meireles, M.A.A. (2014). Production of phenolic-rich extracts from Brazilian plants using supercritical and subcritical fluid extraction: Experimental data and economic evaluation. J Food Eng. 131: 96-109.

Willett, W.C. (1994). Diet and health: What should we eat? Science 264: 532-537.

Xu, B.J., and Chang, S.K.C. (2007). A comparative study on phenolic profiles and antioxidant activities of legumes as affected by extraction solvents. J. Food Sci. 72: S159-S166.

Yao, Y., Cheng, X., Wang, L., Wang, S., and Ren, S. (2011). Biological potential of sixteen legumes in China. Int. J. Mol. Sci. 12: 7048-7058.

Yen, G.-C., and Chen, H.-Y. (1995). Antioxidant activity of various tea extracts in relation to their antimutagenicity. J. Agric. Food Chem. 43: 27-32.

Yeo, J., and Shahidi, F. (2017). Effect of hydrothermal processing on changes of insoluble-bound phenolics of lentils. J. Funct. Foods 38 716-722.

Yeo, J., and Shahidi, F. (2015). Critical evaluation of changes in the ratio of insoluble bound to soluble phenolics on antioxidant activity of lentils during germination. J. Agric. Food Chem. 63: 379-381.

Zduńczyk, Z., Mikulski, D., Jankowski, J., Przybylska-Górnowicz, B., Sosnowska, E., Juśkiewicz, J., Amarowicz, R., and Słomiński, B. (2018). Effects of dietary inclusion of high- and low-tannin faba bean (Vicia faba L.) seeds on microbiota, histology and fermentation processes of the gastrointestinal tract in finisher turkeys. Anim. Feed Sci. Technol. 240: 184-196.

Zhang, B., Peng, H., Deng, Z., and Rong Tsao, R. (2018). Phytochemicals of lentil (Lens culinaris) and their antioxidant and anti-inflammatory effects. J. Food Bioact. 1: 93-103. 